\title{
The correlation between posterior cruciate ligament buckling sign and meniscofemoral ligaments: A radiological study
}

\author{
Abdulkadir Polat, $\mathrm{MD}^{1}{ }^{\mathbb{D}}$, Nihat Acar, $\mathrm{MD}^{2}$ (D) Ahmet Aybar, $\mathrm{MD}^{1}{ }^{(\mathbb{D})}$, Firat Fidan, $\mathrm{MD}^{3}$ (D), \\ Erdem Özden, MD ${ }^{1}$, Okan Gürkan ${ }^{4}$ (D) \\ ${ }^{1}$ Department of Orthopedics and Traumatology, Gaziosmanpaşa Training and Research Hospital, Istanbul, Turkey \\ 2Department of Orthopedics and Traumatology, Çatalca llyas Çokay State Hospital, Istanbul, Turkey \\ ${ }^{3}$ Department of Orthopedics and Traumatology, Sancaktepe Şehit Prof. Dr. Ilhan Varank Training and Research Hospital, Istanbul, Turkey \\ ${ }^{4}$ Department of Radiology, Gaziosmanpaşa Training and Research Hospital, Istanbul, Turkey
}

The close correlation between the anatomy and function of the menisci and cruciate ligaments contributes to the fact that injury of the knee joint internal structures is rarely recognized as an isolated entity rather than other comorbidities of the internal structures. ${ }^{[1,2]}$ Different radiological techniques and signs have been described to help orthopedic surgeons and radiologists to assess musculoskeletal pathologies and plan for surgical interventions. ${ }^{[3,4]}$ Magnetic resonance imaging (MRI) is the gold-standard non-invasive modality for diagnosing injury of the knee joint. ${ }^{[4]}$ Many authors evaluating the sensitivity of MRI in assessing anterior cruciate ligament (ACL) injury have described good, but variable results. ${ }^{[4,5]}$ Therefore, variant MRI signs have been described in

Received: December 23, 2020

Accepted: March 21, 2021

Published online: June 11, 2021

Correspondence: Abdulkadir Polat, MD. Gaziosmanpaşa Eğitim ve Arasstırma Hastanesi Ortopedi ve Travmatoloji Kliniği,

34255 Gaziosmanpaşa, İstanbul, Türkiye.

E-mail: abdulkadirpolat@gmail.com

Doi: $10.52312 / j d r s .2021 .52$

Citation: Polat A, Acar N, Aybar A, Fidan F, Özden E, Gürkan O. The correlation between posterior cruciate ligament buckling sign and meniscofemoral ligaments: A radiological study. Jt Dis Relat Surg 2021;32(2):371-376.

C2021 All right reserved by the Turkish Joint Diseases Foundation

This is an open access article under the terms of the Creative Commons Attribution-NonCommercial License, which permits use, distribution and reproduction in any medium, provided the original work is properly cited and is not used for commercial purposes (http://creativecommons.org/licenses/by-nc/4.0/).

\section{ABSTRACT}

Objectives: This study aims to investigate the correlation between posterior cruciate ligament (PCL) buckling phenomena and the presence or absence of the anterior meniscofemoral ligament (aMFL).

Patients and methods: Between January 2012 and January 2019, magnetic resonance imaging of a total of knee joints of 199 patients (163 males, 16 females; mean age: $31.5 \pm 5.3$ years; range, 18 to 40 years) were reviewed retrospectively. The patients were divided into four groups. The first group included 32 patients with a ruptured anterior cruciate ligament (ACL) and absent aMFL. The second group included 67 patients with a ruptured ACL and apparent aMFL. The third group included 23 patients with an intact ACL and absent aMFL, and the fourth group included 77 patients with an intact ACL and apparent aMFL. The PCL angle was used to measure the buckling degree of the ligament, as calculated as the angle between two lines drawn through the tibial and femoral central portions of the PCL insertions. We assessed the buckling phenomena of the PCL in ACL-ruptured and ACL-intact knees and examined a possible correlation between the PCL buckling angle and the presence or absence of the aMFL of Humphrey.

Results: In the ruptured ACL groups (Groups 1 and 2), the mean PCL buckling angle values were $133.88 \pm 6.32$ and $104.83 \pm 7.34$ degrees, respectively. A significant difference was detected between both groups $(p=0.026)$. In the intact ACL groups (Groups 3 and 4), the mean PCL buckling angle values were $143.47 \pm 5.96$ and $116.77 \pm 8.38$ degrees, respectively. A significant difference was detected between both groups $(p=0.039)$. No statistically significant difference was observed between Groups 1 and $3(\mathrm{p}=0.13)$ and between Groups 2 and 4 $(\mathrm{p}=0.088)$.

Conclusion: The PCL buckling sign is not specific for ACL ruptures, and can be seen frequently in normal knee joints which it is strongly associated with the presence of aMFL of Humphrey.

Keywords: Knee joint, magnetic resonance imaging, meniscofemoral ligament, posterior cruciate ligament buckling. 
an attempt to improve the accuracy of ACL injury diagnosis. ${ }^{[4-6]}$ Sagittal MRIs of the knee joint often show what is called the buckled (sigmoid) posterior cruciate ligament (PCL) sign, which is considered one of the indirect or secondary signs sought by radiologists and orthopedic surgeons to confirm the diagnosis of ACL rupture. ${ }^{[6,7]}$ Buckling of PCL can be seen in both normal individuals and in patients with ACL ruptures. Several studies have shown an association between the PCL curved appearance and ACL chronic ruptures rather than acute ruptures. ${ }^{[6-8]}$

The PCL angle is used to determine the buckling degree of the ligament, which is calculated as the angle between two lines drawn through the tibial and femoral central portions of the PCL insertions (Figure 1). ${ }^{[9]}$ An angle of $<105^{\circ}$ was accepted as buckling of PCL, and an indirect predictor of ACL rupture. ${ }^{[10,11]}$ The meniscofemoral ligaments (MFLs) are strong straight bands of collagen attaching the posterior aspect of the menisci to the femoral intercondylar area. In most cases, the lateral meniscus posterior horn is attached to the inner lateral aspect of the medial femoral condyle by the MFLs. The anterior meniscofemoral ligament (aMFL) of Humphrey crosses anterior to the PCL,

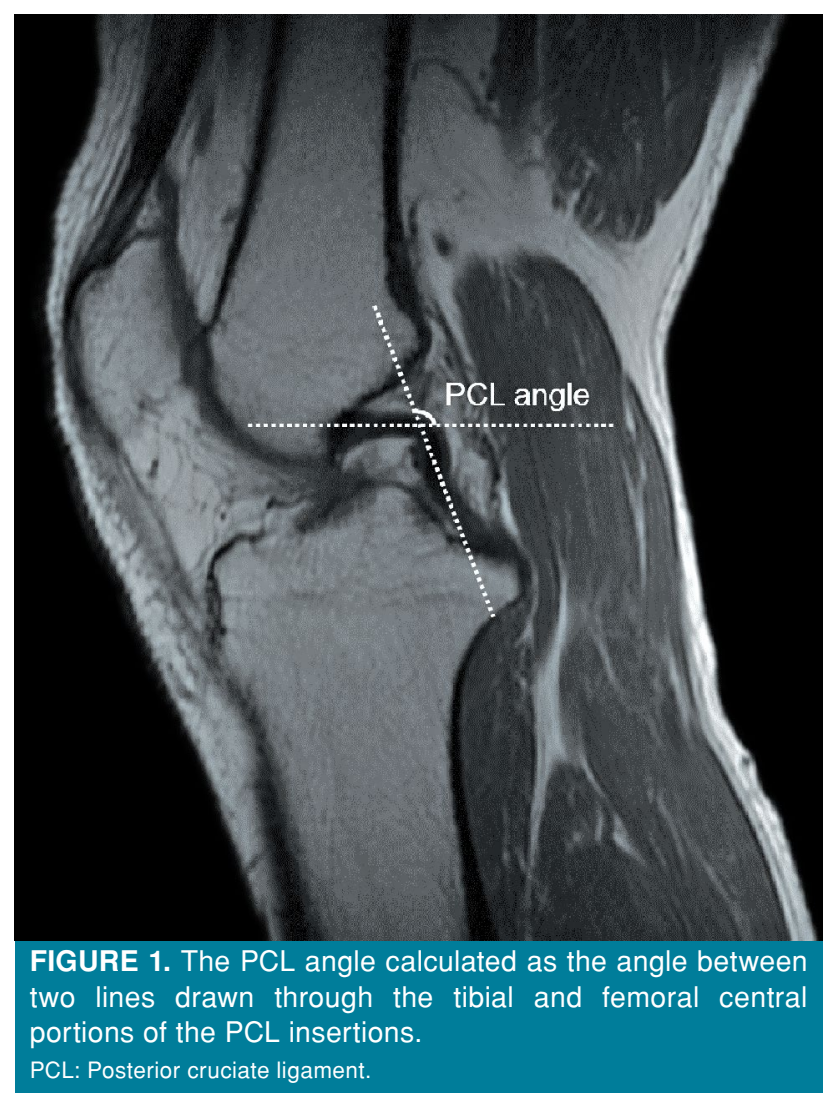

while the posterior meniscofemoral ligament (pMFL) of Wrisberg passes directly posterior to the PCL (Figure 2).[12,13]

Over the last few decades, several anatomical and radiological studies of MFLs have been carried out. A study of Heller and Langman ${ }^{[14]}$ demonstrated that at least one MFL was found in $71 \%$ of the studied specimens, while another study showed that the incidence was close to $100 \%{ }^{[15]}$ Race and Amis $^{[16]}$ also showed that Wrisberg ligament was present in $64.4 \%$ of individuals, whereas Humphrey ligament was present in $27.8 \%$. Anatomical texts have variable discrepancies regarding MFLs. Some have described one or both MFLs, whereas others have not mentioned about their existence. Recently, there has been a renewed concern regarding the MFLs. A biomechanical study demonstrated that MFLs could have a stabilizing function in the knee joint and share common properties with the posterior bundle of the PCL. ${ }^{[17]}$ Since PCL buckling phenomena is considered a strong predictor of ACL rupture in several studies, in the present study, we hypothesized that PCL buckling sign was not a pure secondary sign associated with anterior tibial translation resulting from ACL injury, but it could be also present in normal knees without an ACL tear. We, therefore, aimed to assess the buckling phenomena of the PCL in ACL-ruptured and ACL-intact knees and to correlate the PCL buckling angle with the presence or absence of the aMFL of Humphrey.

\section{PATIENTS AND METHODS}

This single-center, retrospective study was conducted at Istanbul Gaziosmanpaşa Training and Research Hospital, Department of Orthopedics and Traumatology between January 2012 and January 2019. The MRI scans of knees of a total of 638 patients were initially screened. Patients with a history of rheumatic diseases, posttraumatic arthritis, degenerative arthritis, advanced age (above 70 years) and articular or periarticular fractures were excluded from this study. Those younger than 70 years without advanced radiological signs of osteoarthritis and associated knee comorbidities with or without ACL rupture were recruited. Finally, a total of 199 patients (163 males, 16 females; mean age: $31.5 \pm 5.3$ years; range, 18 to 40 years) who fulfilled the eligibility criteria were included in this study. A written informed consent was obtained from each patient. The study protocol was approved by the Istanbul Gaziosmanpaşa Training and Research Hospital Ethics Committee (No: 117/2019). The study was 

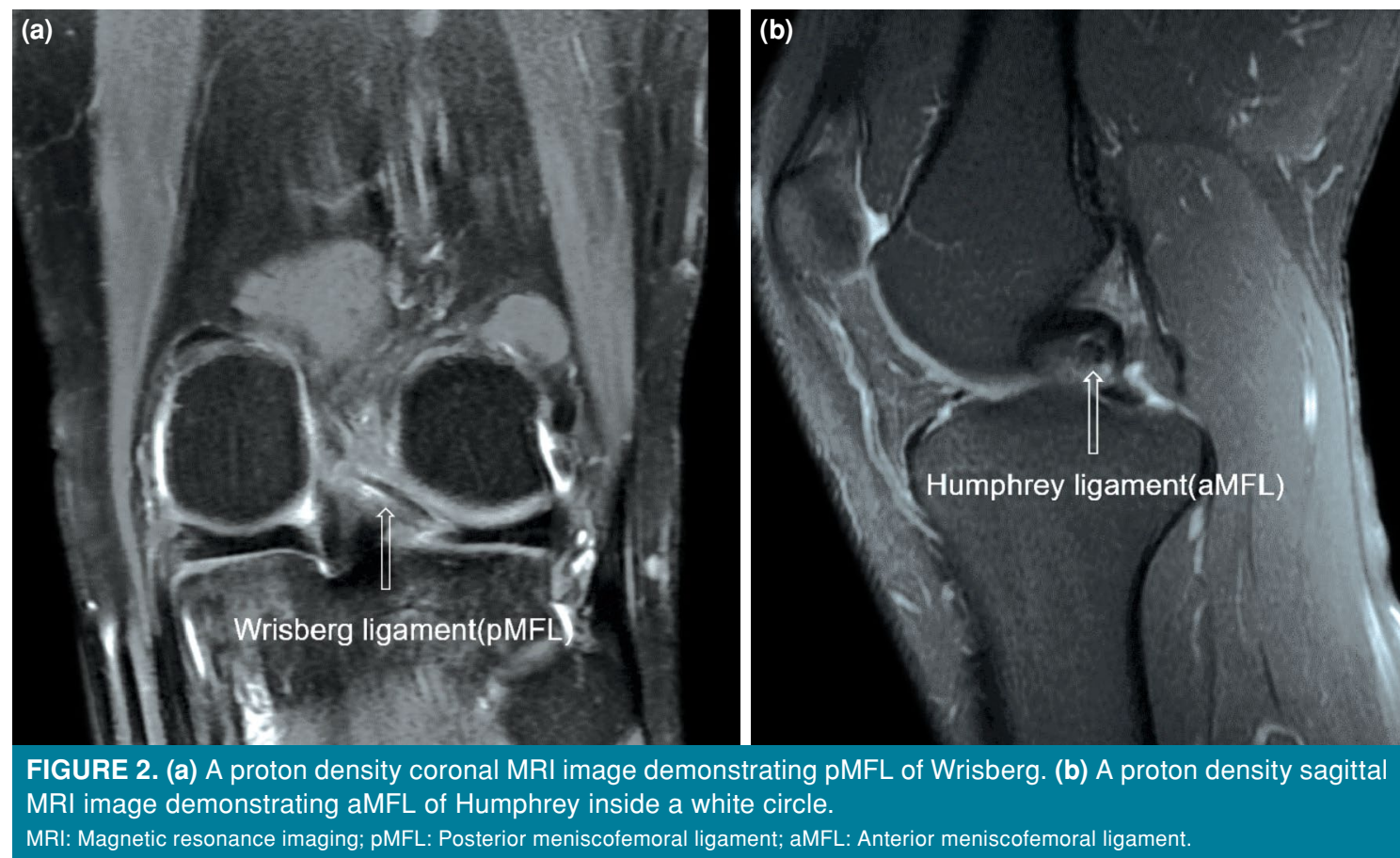

FIGURE 2. (a) A proton density coronal MRI image demonstrating pIMI
MRI image demonstrating aMFL of Humphrey inside a white circle.

MRI: Magnetic resonance imaging; pMFL: Posterior meniscofemoral ligament; aMFL: Anterior meniscofemoral ligament.

conducted in accordance with the principles of the Declaration of Helsinki.

The patients were divided into four groups. The first group was consisted of 32 patients with a ruptured ACL and absent aMFL of Humphrey. The second group included 67 patients with a ruptured ACL and apparent Humphrey ligament. The third group included 23 patients with an intact ACL and absent Humphrey ligament. The fourth group included 77 patients with an intact ACL and apparent Humphrey ligament (Figure 3).

The 1.5-T magnet MRI system (Magnetom Essenza; Siemens Healthineers, Japan) with a dedicated solenoid surface knee coil was used in this study. All imaging studies were accomplished using the surface coil with the knee joint in extended position with a minimal external rotation. Cushions were placed around the knee to restrict motion. Sagittal, coronal, and axial images were obtained with a 2 to $14-\mathrm{cm}$ field of view, a $256 \times 256$ matrix, one excitation, a TR of 600 to $2000 \mathrm{msec}$, and a dual-echo TE of 20 and 60 to $80 \mathrm{msec}$. Slice thickness was $2-\mathrm{mm}$ with a $1-\mathrm{mm}$ gap. The frequency encoding direction was always in the cephalocaudal axis to avoid wrap-around artifact. Sagittal, coronal, and axial images for each patient were examined thoroughly by the same radiologist to determine the presence or absence of aMFL of Humphrey, PCL buckling angle and the ACL integrity condition (Table I). For MRI interpretation of aMFL, special attention was paid to sagittal and coronal PD-WI and T2-WI sequences. The aMFL was observed in coronal images as a thin linear band with a low signal intensity anterior to PCL, whereas it appeared on sagittal images as a low MR signal dot-like, located anterior to aMFL. The appearance of aMFL was better evaluated on sagittal images. Therefore, the appearance of aMFL on sagittal sequences was the only inclusion criterion of the presence or absence of aMFL for the patients included in this study.

\section{Statistical analysis}

Statistical analysis was performed using the PASW version 18.0 software (SPSS Inc., Chicago, IL, USA). Descriptive data were expressed in mean \pm standard deviation (SD), median (min-max) or number and frequency, where applicable. The Mann-Whitney U test was used to detect the statistical significance between the groups. A $p$ value of $<0.05$ was considered statistically significant.

\section{RESULTS}

Demographic and clinical data of the patients are summarized in Table I. In the ruptured ACL groups (Groups 1 and 2), the mean PCL buckling angle values were $133.8 \pm 6.3$ and $104.8 \pm 7.3$ degrees, respectively. A statistically significant difference was detected between Groups 1 and $2(p=0.026)$. In the 

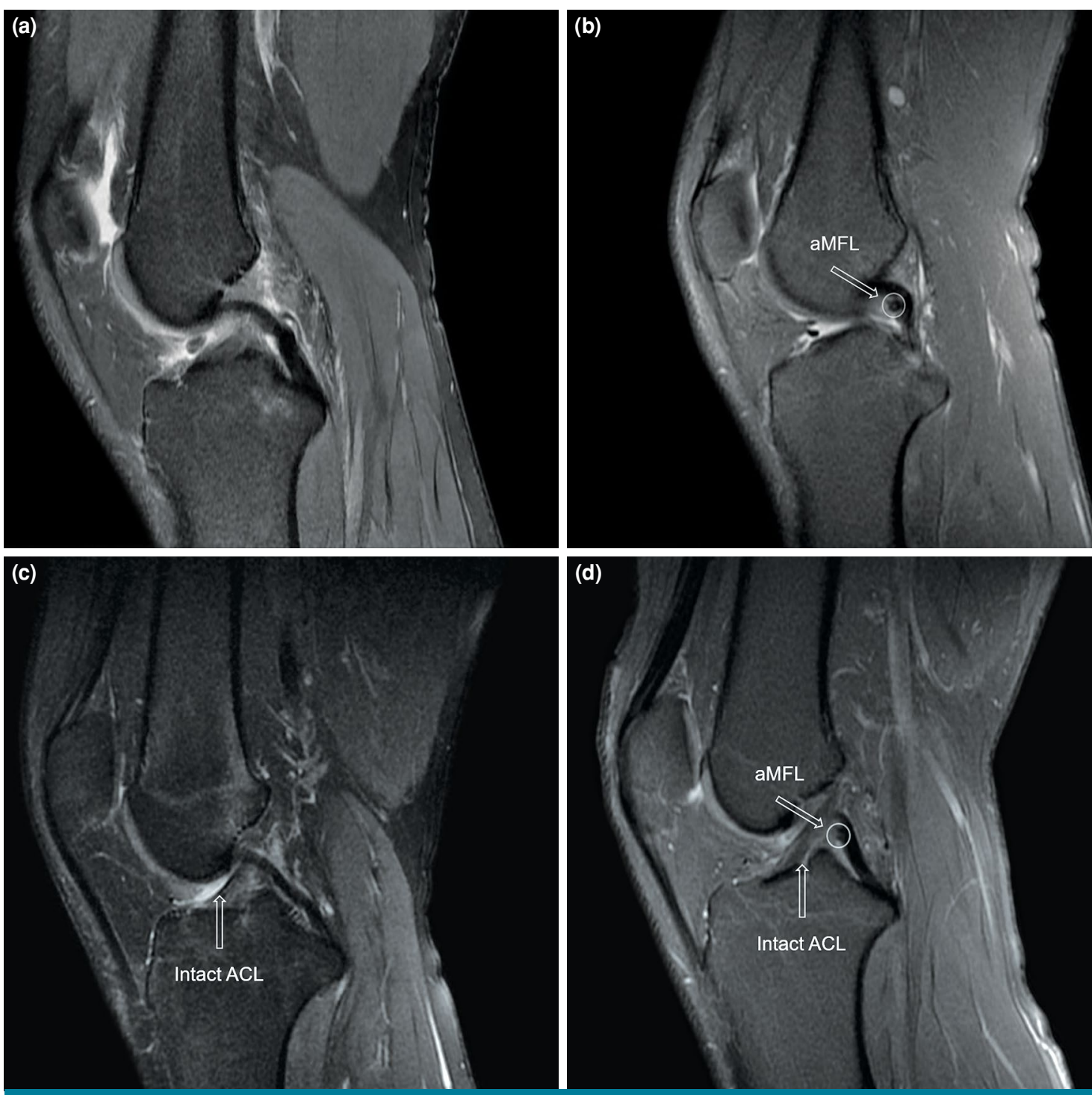

FIGURE 3. A sagittal proton density MRI images showing (a) a ruptured ACL with an absent aMFL of Humphrey with a flattened non-buckled PCL; (b) a ruptured ACL with an apparent aMFL of Humphrey and a hyperbuckled sigmoid PCL morphology; (c) an intact ACL with an absent aMFL of Humphrey and hypo-buckled PCL morphology; (d) an intact ACL with an apparent aMFL of Humphrey and associated hyper-buckled PCL morphology.

MRI: Magnetic resonance imaging; aMFL: Anterior meniscofemoral ligament; PCL: Posterior cruciate ligament; ACL: Anterior cruciate ligament.

\section{TABLE I}

Demographic and clinical characteristics of patients

\begin{tabular}{|lcccccc|}
\hline & $n$ & Mean \pm SD & Female/Male & $\begin{array}{c}\text { PCL angle } \\
\text { Mean } \pm S D\end{array}$ & ACL condition & $\begin{array}{c}\text { Humphrey ligament } \\
\text { condition }\end{array}$ \\
\hline Group 1 & 32 & $30.8 \pm 4.9$ & $2 / 30$ & $133.2 \pm 6.3$ & Ruptured & Absent \\
Group 2 & 67 & $29.6 \pm 5.3$ & $9 / 58$ & $104.8 \pm 7.3$ & Ruptured & Present \\
Group 3 & 23 & $31.9 \pm 4.7$ & $3 / 20$ & $143.5 \pm 6.0$ & Intact & Absent \\
Group 4 & 77 & $33.4 \pm 5.8$ & $12 / 55$ & $116.8 \pm 8.4$ & Intact & Present \\
\hline \multicolumn{7}{l}{ SD: Standard deviation; PCL: Posterior cruciate ligament; ACL: Anterior cruciate ligament. } \\
\end{tabular}


intact ACL groups (Groups 3 and 4), the mean PCL buckling angle values were $143.5 \pm 6.0$ and $116.8 \pm 8.4$ degrees, respectively, indicating a statistically significant difference between the groups $(p=0.039)$. However, there was no statistically significant difference was observed between Groups 1 and 3 $(p=0.13)$ and between Groups 2 and $4(p=0.088)$.

\section{DISCUSSION}

Our study revealed that PCL buckling was not a secondary sign specific for ACL tear, but it could be also noticed frequently with intact ACL, which is mostly associated with the presence of an intact aMFL. ${ }^{[18]}$

Many secondary signs have been described to help in the accurate diagnosis of ACL ruptures on MRI, one of which is the buckled PCL sign.$^{[8]}$ Many studies have accepted the buckled PCL sign to be a good predictor of ruptured ACL. ${ }^{[9-11]}$ According to some studies, anterior subluxation of tibia more than $5 \mathrm{~mm}$ is considered a strong secondary sign of ACL tear. It has been shown that anterior displacement of the tibia relative to the femur creates morphological changes in the shape of the PCL to a sigmoid or an over-buckled shape. ${ }^{[19]}$ The PCL angle changes have been intensively studied by Choi et al. ${ }^{[20]}$ The authors suggested that PCL buckling angle was a significant predictor of chronic ACL tears and related to anterior tibial subluxation. However, Yoo and $\operatorname{Lim}^{[21]}$ found a weak association between the buckling angle of the PCL and the anterior instability and, therefore, on MRI images, the buckling of PCL was not directly associated with anterior instability. Therefore, they concluded that the buckling of PCL decreased obviously after ACL reconstruction surgery. Rak et al. ${ }^{[22]}$ demonstrated that the buckling of PCL after ACL reconstruction was mainly due to ACL graft laxity. Horton et al. ${ }^{[19]}$ showed that the buckling of PCL was present in $37.5 \%$ of full-thickness, in $43 \%$ of partial ACL graft tears, and in $30 \%$ of intact ACL grafts. Their study revealed that the buckling of PCL had $70 \%$ specificity, $41 \%$ sensitivity, $76 \%$ positive predictive, and $35 \%$ negative predictive values for diagnosing partial-thickness and full-thickness tears of ACL grafts after surgery. The meniscofemoral ligaments are strong collagenous fibrous band in the knee. The anterior branch of these ligaments is the ligament of Humphrey, which is anterior to the PCL. ${ }^{[23]}$ Recent studies have demonstrated a correlation between trauma mechanism of ACL rupture and posterior root of the lateral meniscus with a concomitant MFL injury. ${ }^{[24,25]}$ The functional synergisms between PCL and MFLs have been shown on many aspects. ${ }^{[25]}$ In the development of osteoarthritis of the knee joint, damaged MFLs may constitute an additional risk factor mostly due to the increased femorotibial contact pressure. ${ }^{[26]}$ According to Forkel et al., ${ }^{[24]}$ one MFL at least was found in $94.4 \%$ of cases. Contrary to other studies where the aMFL was present in approximately 24 to $36 \%$, ${ }^{[25-27]}$ the present study showed that the incidence of aMFL of Humphrey was $72.3 \%$. This finding is consistent with a previous study of Röhrich et al. ${ }^{[28]}$ Of 199 knee MRI examinations, aMFL was seen in 144 patients in Groups 2 and 4. Despite the presence or absence of ACL tear, the presence of aMFL was closely correlated with a buckled PCL morphology on sagittal MRI images and demonstrated a close association with low mean PCL buckling angle values of $104.8 \pm 7.3$ and $116.8 \pm 8.4$ degrees, respectively. On the other hand, in Groups 1 and 3, despite the injury condition of the ACL, the absence of aMFL was closely correlated with a more flattened PCL morphology on sagittal MRI images and demonstrated high mean PCL buckling angle values of $133.9 \pm 6.3$ and $143.5 \pm 6.0$ degrees. respectively. To our understanding, depending on the size and the thickness, the presence of an intact aMFL creates a fulcrum in front of PCL, leading to the hyper-buckling morphology which is frequently visualized on sagittal MRI images. Although PCL buckling has been described in several patients with an absent aMFL, non-visualization of aMFL on MRI does not exclude its total absence, since MRI is only $85 \%$ sensitive and $75 \%$ specific in detecting MFLs. ${ }^{[26,27]}$

In this study, the increased PCL buckling was associated with the presence of Humphrey ligament. Since PCL buckling sign has been described in many cases without associated ACL rupture, it cannot be considered a specific secondary sign of ACL injury. It is mostly associated with an intact Humphrey ligament where the PCL curls upon the intact aMFL to create the MRI buckling morphology of the PCL.

On the other hand, similar to other studies, this study has certain limitations. Being a retrospective radiological study reported by a single radiologist is the main limitation, since the MRI reliability in detecting presence or absence of MFLs is not high compared to ACL pathology. In addition, the retrospective nature of this study design does not permit any surgical or arthroscopic correlations. Using a 1.5-T magnet MRI system is another limitation, as more sophisticated MRI systems may provide more reliable interpretation of the MFLs condition. 
In conclusion, PCL buckling is not a secondary sign specific for ACL tear, it can also be noticed frequently with intact ACL, and it is mostly associated with the presence of an intact aMFL. Further anatomical and radiological studies should be conducted to assess the variant morphologies of aMFL of Humphry and its close correlation with the buckling phenomena of the PCL.

\section{Declaration of conflicting interests}

The authors declared no conflicts of interest with respect to the authorship and/or publication of this article.

\section{Funding}

The authors received no financial support for the research and/or authorship of this article.

\section{REFERENCES}

1. Türker M, Cetik O, Cirpar M, Yalçınozan M, Cömert RB, Simşek T. Kova sapı menisküs yırtığı tanısında manyetik rezonans görüntüleme bulgularının etkinliği. Eklem Hastalik Cerrahisi. 2012;23(3):145-9.

2. Takahashi T, Kimura M, Takeshita K. MRI evaluation of the ACL remnant tissue in ACL-deficient knee. J Orthop Surg (Hong Kong) 2017;25:2309499017739479.

3. Acar N, Karaarslan A, Karakasli A, Erduran M. Femoral head fovea capitis variant configurations and age related changes-A radiological study. Iran J Radiol 2017;14:e41130.

4. Chung HW, Ahn JH, Ahn JM, Yoon YC, Hong HP, Yoo SY, et al. Anterior cruciate ligament tear: Reliability of MR imaging to predict stability after conservative treatment. Korean J Radiol 2007;8:236-41.

5. Dufka FL, Lansdown DA, Zhang AL, Allen CR, Ma CB, Feeley BT. Accuracy of MRI evaluation of meniscus tears in the setting of ACL injuries. Knee 2016;23:460-4.

6. Chan WP, Peterfy C, Fritz RC, Genant HK. MR diagnosis of complete tears of the anterior cruciate ligament of the knee: importance of anterior subluxation of the tibia. AJR Am J Roentgenol 1994;162:355-60.

7. Lee JK, Yao L, Phelps CT, Wirth CR, Czajka J, Lozman J. Anterior cruciate ligament tears: MR imaging compared with arthroscopy and clinical tests. Radiology 1988;166:861-4.

8. Ahn JM, Kang HS, Kim SM. Injury of the ligaments of the knee: magnetic resonance evaluation. J Korean Radiol Soc 1992;28:269-74.

9. Yoon JP, Chang CB, Yoo JH, Kim SJ, Choi JY, Choi JA, et al. Correlation of magnetic resonance imaging findings with the chronicity of an anterior cruciate ligament tear. J Bone Joint Surg [Am] 2010;92:353-60.

10. McCauley TR, Moses M, Kier R, Lynch JK, Barton JW, Jokl P. MR diagnosis of tears of anterior cruciate ligament of the knee: Importance of ancillary findings. AJR Am J Roentgenol 1994;162:115-9.

11. Moore SL. Imaging the anterior cruciate ligament. Orthop Clin North Am 2002;33:663-74.
12. Yamamoto M, Hirohata K. Anatomical study on the menisco-femoral ligaments of the knee. Kobe J Med Sci 1991;37:209-26.

13. Wan AC, Felle P. The menisco-femoral ligaments. Clin Anat 1995;8:323-6.

14. Heller L, Langman J. The menisco-femoral ligaments of the human knee. J Bone Joint Surg [Br] 1964;46:307-13.

15. Kusayama T, Harner CD, Carlin GJ, Xerogeanes JW, Smith BA. Anatomical and biomechanical characteristics of human meniscofemoral ligaments. Knee Surg Sports Traumatol Arthrosc 1994;2:234-7.

16. Race A, Amis AA. The mechanical properties of the two bundles of the human posterior cruciate ligament. J Biomech 1994;27:13-24.

17. Clancy WG Jr, Shelbourne KD, Zoellner GB, Keene JS, Reider B, Rosenberg TD. Treatment of knee joint instability secondary to rupture of the posterior cruciate ligament. Report of a new procedure. J Bone Joint Surg [Am] 1983;65:310-22.

18. Atik OŞ. Is there something new and interesting in my article? Eklem Hastalik Cerrahisi 2019;30:69.

19. Horton LK, Jacobson JA, Lin J, Hayes CW. MR imaging of anterior cruciate ligament reconstruction graft. AJR Am J Roentgenol 2000;175:1091-7.

20. Choi NH, Kim MK, Yoon YJ, Yoo JD, Lee HM. Morphological change of PCL of MRI in the tear of ACL. J Korean Orthop Assoc 1996;31:371-76.

21. Yoo JD, Lim HM. Morphologic changes of the posterior cruciate ligament on magnetic resonance imaging before and after reconstruction of chronic anterior cruciate ligament ruptures. Knee Surg Relat Res 2012;24:241-4.

22. Rak KM, Gillogly SD, Schaefer RA, Yakes WF, Liljedahl RR. Anterior cruciate ligament reconstruction: evaluation with MR imaging. Radiology 1991;178:553-6.

23. Brantigan OC, Voshell AF. Ligaments of the knee joint; The relationship of the ligament of Humphry to the ligament of Wrisberg. J Bone Joint Surg [Am] 1946;28:66.

24. Forkel P, Reuter S, Sprenker F, Achtnich A, Herbst E, Imhoff A, et al. Different patterns of lateral meniscus root tears in ACL injuries: Application of a differentiated classification system. Knee Surg Sports Traumatol Arthrosc 2015;23:112-8.

25. Amis AA, Gupte CM, Bull AM, Edwards A. Anatomy of the posterior cruciate ligament and the meniscofemoral ligaments. Knee Surg Sports Traumatol Arthrosc 2006;14:257-63.

26. Alizai H, Roemer FW, Hayashi D, Crema MD, Felson DT, Guermazi A. An update on risk factors for cartilage loss in knee osteoarthritis assessed using MRIbased semiquantitative grading methods. Eur Radiol 2015;25:883-93.

27. Cho JM, Suh JS, Na JB, Cho JH, Kim Y, Yoo WK, et al. Variations in meniscofemoral ligaments at anatomical study and MR imaging. Skeletal Radiol 1999;28:189-95.

28. Röhrich S, Kainberger F, Hirtler L. Evaluation of agedependent morphometrics of the meniscofemoral ligaments in reference to the posterior cruciate ligament in routine MRI. Eur Radiol 2018;28:2369-79. 